\title{
The Interplay between Reproductive Social Stimuli and Adult Olfactory Bulb Neurogenesis
}

\author{
Paolo Peretto, ${ }^{1,2}$ Roberta Schellino, ${ }^{1,2}$ Silvia De Marchis, ${ }^{1,2}$ and Aldo Fasolo ${ }^{1,2}$ \\ ${ }^{1}$ Department of Life Sciences and Systems Biology, University of Turin, Via Accademia Albertina 13 ,10123 Torino, Italy \\ ${ }^{2}$ Neuroscience Institute Cavalieri Ottolenghi (NICO), Regione Gonzole 10, Orbassano, 10043 Torino, Italy \\ Correspondence should be addressed to Paolo Peretto; paolo.peretto@unito.it
}

Received 22 April 2014; Accepted 19 June 2014; Published 22 July 2014

Academic Editor: Heather Cameron

Copyright (C) 2014 Paolo Peretto et al. This is an open access article distributed under the Creative Commons Attribution License, which permits unrestricted use, distribution, and reproduction in any medium, provided the original work is properly cited.

\begin{abstract}
Adult neurogenesis is a striking form of structural plasticity that adapts the brain to the changing world. Accordingly, new neuron production is involved in cognitive functions, such as memory, learning, and pattern separation. Recent data in rodents indicate a close link between adult neurogenesis and reproductive social behavior. This provides a key to unravel the functional meaning of adult neurogenesis in biological relevant contexts and, in parallel, opens new perspectives to explore the way the brain is processing social stimuli. In this paper we will summarize some of the major achievements on cues and mechanisms modulating adult neurogenesis during social behaviors related to reproduction and possible role/s played by olfactory newborn neurons in this context. We will point out that newborn interneurons in the accessory olfactory bulb (AOB) represent a privileged cellular target for social stimuli that elicit reproductive behaviors and that such cues modulate adult neurogenesis at two different levels increasing both proliferation of neuronal progenitors in the germinative regions and integration of newborn neurons into functional circuits. This dual mechanism provides fresh neurons that can be involved in critical activities for the individual fitness, that is, the processing of social stimuli driving the parental behavior and partner recognition.
\end{abstract}

\section{Introduction}

Since its rediscovery in the early 90 s, the field of adult neurogenesis (AN) has been the object of a large number of studies in order to define its extent and role in the normal brain function, but also to develop new strategies for brain repair. After 30 years of intense research, although the potential use of $\mathrm{AN}$ as a ready-made tool in therapy remains elusive (see, for discussion, http://www.frontiersin.org/neurogenesis/researchtopics/adult_neurogenesis_twenty_year/1785 and [1]), its role on brain physiology appears astonishing in the context of adult neural plasticity. AN seems crucial to optimize the plastic responses of the brain in multiple sensory contexts [2]. This important function is achieved through a continuous supply of new neurons into the circuits of the olfactory bulb (OB) and dentate gyrus (DG) of hippocampus, two key regions exerting an important control on brain circuits critical for survival of individuals and species $[3,4]$.

Newborn neurons show unique functional properties, such as lower threshold for synaptic and structural plasticity, and increased responsiveness to experienced stimuli [5-7], supporting a role for $\mathrm{AN}$ in mechanisms of memorization and learning [8]. In addition, recent evidences indicate that integration of "young and excitable" neurons in the DG and OB improves the pattern separation, namely, the ability to distinguish/discriminate between similar/overlapping sensory experiences $[2,9-12]$. On the whole, AN is considered as a life-long mechanism, which adapts the brain circuits of each individual according to the environmental complexity and novelty, following a simple rule: more experiences need more cognitive challenges requiring plasticity and in turn more AN [13]. Addition of newborn neurons in the adult brain is orchestrated by a complex interplay between internal and external environmental cues that can either positively or negatively influence different aspects of the neurogenic process (e.g., proliferation of progenitors, migration, differentiation, and survival of neuroblasts) beyond its baseline, which is maintained by an intrinsic control [14-16]. Recently, it has been shown that salient cues such as pheromones released during intersexual and parent-offspring interaction, 
or pregnancy and postpregnancy hormones, regulate $\mathrm{AN}$ [17], thus suggesting a role for $\mathrm{AN}$ in the reproductive function (see also [18] for recent discussion). Many questions remain open, as the molecular nature of the cues and the brain circuits underlying the link between reproductive behavior and AN. In this paper, we emphasize that the identification of such players besides tackling the study of AN in biologically relevant contexts gives the chance to investigate how sensory stimuli promoting reproductive behavior are processed in the adult brain. In addition, it also offers a key to understand how the occurrence of $\mathrm{AN}$ in two restricted brain regions can impact the whole brain function. Hence, we will briefly describe recent findings linking reproductive social stimuli to AN. Then, we will focus on the accessory olfactory bulb of adult female mice $[12,19]$ to discuss the role of AN as a mediator of a striking example of sexual behavior, the mate pheromonal imprinting to avoid pregnancy block in female mice [20].

\section{Adult Neurogenesis and Reproductive Social Stimuli: Some Major Key Points}

Physiological modulation of AN has been described in multiple reproductive social behaviors (see for review [17, 21]). The emergence of such behavioral aspects implies multisensory integration with the endocrine system [3, 22, 23].

Pheromonal cues, which convey information about species specificity, gender, social status, health, genetic advantage, and individual recognition [24], have been demonstrated as major stimuli to enhance neurogenesis in the adult brain $[12,19,25-30]$. A direct contact (fully exploration of pheromonal cues and/or coupling) between individuals or with the stimulus (bedding or urine) is necessary to modulate AN $[12,19,25-40]$. Thus, activation of both the main and the accessory olfactory systems, which cooperate in the control of reproductive behavior $[41,42]$, is required to enhance AN in this context. The relative contribution of the two olfactory pathways on the neurogenic process triggered by olfactory social stimuli remains however poorly understood.

Exposure to semiochemicals, such as those released during sex and parent-offspring interactions, elicits neurogenesis in both SVZ and DG niches [26, 28]. By contrast, exposure to "generic odorants," or physical activity and environmental enrichment, selectively regulates $\mathrm{AN}$ in the SVZ or in the DG, respectively $[43,44]$. These data indicate that only salient chemosensory stimuli can trigger neurogenesis simultaneously in both SVZ and DG, possibly through a reciprocal interaction between the two neurogenic niches (see [45] for discussion regarding this point).

$\mathrm{AN}$ is also modulated during pregnancy or pseudopregnancy, lactation $[32,46]$, and in pacing behavior $[38,40]$, activities that require high-level integration among different brain regions and the endocrine system. The anterior pituitary hormone prolactin (PRL) has been identified as one of the main endogenous cues promoting proliferation of SVZ progenitors in the reproductive context [26-28, $32,46]$, suggesting a cooperation between hormones and brain plasticity to generate proper physiological and behavioral responses to the external stimuli [23]. PRL in female rodents rises during mating [47], pregnancy and lactation [48], and after prolonged exposure to male pheromones [27]. Socially induced release of PRL increases proliferation of SVZ progenitor cells, raising the number of newborn neurons integrating into the $\mathrm{OB}$ circuits of female mice 15-20 days thereafter. Such an increase is matching with the postpartum period $[26,27,32]$. Hence, PRL-induced proliferation occurring in early gestation is possibly required later on for the expression of normal maternal behaviors during the postpartum period (e.g., pup recognition). It is to note that in the postpartum period, which is characterized by profound hormonal changes [49], cell proliferation in the DG of female rats is reduced [50] and in the SVZ of mice is marked by peculiar fluctuations [32]. Interestingly enough, PRL increases neurogenesis also in male mice during interaction with their own pups, both in SVZ and in DG of hippocampus [28]. Considering the multifaceted role of this hormone in favoring the parental care behavior [48], the PRLinduced neurogenesis might be regarded as a mechanism of neural plasticity eliciting offspring survival [46], although Xray irradiation of SVZ [36] and genetically targeted ablation of newborn neurons [39] failed to show significant alteration of such behavior.

Exposure to dominant male semiochemicals, besides increasing SVZ neurogenesis through PRL release, enhances cell proliferation in the DG of females via the luteinizing hormone (LH), another hypothalamic-pituitary axis hormone [26]. LH is a well-known mediator of social and reproductive functions [51]. Mak and colleagues [26] correlated such hormone-mediated neurogenic effect with the mate-choice behavior, since only exposure to male dominant chemosensory cues was able to enhance neurogenesis. In parallel, mate preference was lost in females with impaired $\mathrm{PRL}$ and/or LH function. By large, these data indicate that AN is part of the complex feedback loops linking pheromones, hormones, and reproductive function [52, 53]. According to this view, social and reproductive cues stimulate steroids hormones secretion and a vast literature shows the influence of gonadal hormones on hippocampal neurogenesis (see for review [54]). By contrast, only a few studies have addressed the role of sex steroids in modulating $\mathrm{AN}$ in the $\mathrm{OB}$ region $[25,55-57]$. This is surprising considering the key role played by estradiol in the control of olfactory reproductive behavior in female rodents [58]. Interestingly, Veyrac and Bakker [57] employing aromatase-knockout mice, which are unable to produce estradiol across their life span, demonstrated that estradiol exposure does not influence SVZ progenitor proliferation but rather differentially affects the survival of newborn neurons and their functional responses to male urine cues in the main and accessory OB. Whether the activity of the estradiol is direct or mediated by other hormones/factors deserves further investigation. Similarly, it remains to be clarified which mechanism selectively improves the estradiol-dependent survival of newborn neurons and their responsiveness to chemosensory stimuli in the main and accessory OB. 

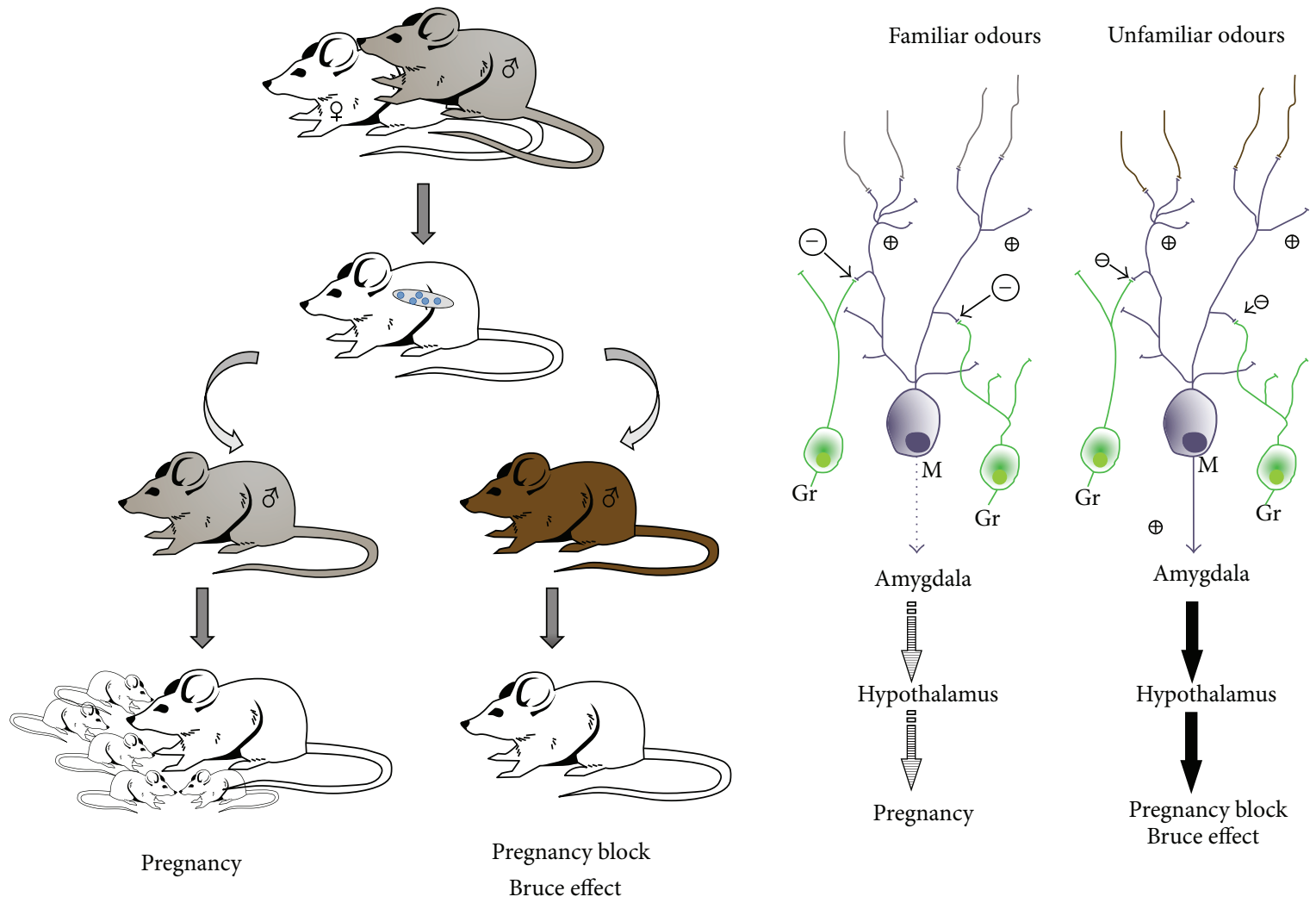

FIGURE 1: The mate pheromonal imprinting is a vomeronasal-dependent sex behavior. When a recently mated female is exposed to an unfamiliar male (brown mice) or unfamiliar male urine, a neuroendocrine reflex leads to pregnancy block and in turn triggers a return to estrus. This male chemosensory-induced block of pregnancy is known as the Bruce effect (see the text for details). The Bruce effect does not occur if the female is exposed to the mate's chemosignals, since in this case a restricted pool of AOB granule interneurons (Gr) efficiently inhibits mitral cell signal transmission to the forebrain nuclei involved in estrus induction. Such kind of "protection" to the mate's pheromones implies the formation of an olfactory recognition memory for the stud male chemosensory cues at the granule-to-mitral synaptic interface in the AOB (right). Gr: granule cells; M: mitral cells (figure modified from [16]).

Besides hormones, other signals/systems participate in the regulation of AN in the social context of reproduction. Pacing behavior is another interesting example of social interaction which modulates $\mathrm{AN}$ in the $\mathrm{OB}$ region of rats $[38,40]$. Pacing behavior in female rats consists of the possibility to control the rate of sexual stimulation they receive [59], a condition that normally occurs when they mate in seminatural or natural conditions [60,61]. Paced mating induces several physiological and behavioral advantages, such as a reward state that assures that the behavior will be repeated in the future $[62,63]$. Using ovariectomized females, hormonally primed to induce sexual behavior, Paredes and colleagues showed that pacing behavior promotes per se an increase in SVZ proliferation that leads to a higher density of new neurons in the accessory $\mathrm{OB}$ [38]. In addition, they found that if the behavior is repeated, this increase involves also the main OB. The effect on AN seems specifically dependent on the ability of controlling the sexual interaction and not due to different levels of estradiol and progesterone, since all the different groups had the same hormone and behavioral levels [63]. Pace mating also enhances SVZ-proliferation in males [40], whose sexual activity with receptive females also increases hippocampal proliferation [37]. The authors suggest that increased neurogenesis during pacing behavior could be related to the rewarding value of the sexual interaction and indicate the opioid system as potential modulator of this effect. Accordingly, administration of the opioid antagonist naloxone blocks the rewarding effect induced by sexual behavior in males and females $[64,65]$ and the opioids modulate AN in the adult brain [66].

In summary, the emerging picture shows that modulation of AN during reproductive social behaviors occurs through multiple exogenous and endogenous cues. These include salient chemosensory signals, adenohypophyseal hormones (e.g., PRL and LH), gonadal hormones, and, potentially, neurotransmitters related to the rewarding value of the sexual interaction. Reproductive social stimuli seem to modulate AN by increasing the proliferation of progenitor cells in both neurogenic niches. In addition, as discussed in detail in the next paragraphs, these stimuli also favor the survival/integration of newborn neurons during a critical timewindow of their maturation $[12,19,30]$. This prosurvival effect on newborn neurons is mostly mediated by male pheromonal cues and prominent in the $\mathrm{AOB}$ of female mice $[11,19,30]$. From now on, by exploiting the mate pheromonal imprinting in female mice as a specific sex behavior and the 
process of AN occurring in the $\mathrm{AOB}$ of rodents, we will focus on a remarkable example of the interplay occurring between $\mathrm{AN}$ and reproductive activity.

\section{The Mate Pheromonal Imprinting: A Vomeronasal-Dependent Sex Behavior of Female Mice}

The mate pheromonal imprinting is an olfactory recognition process for mate's pheromones, which prevents the pregnancy block effect (also known as the Bruce effect) that occurs during a critical postmating window in adult female mice [67] (Figure 1). If a recently mated female is exposed to chemosignals contained in urine from an unfamiliar male, a neuroendocrine reflex leads to the block of pregnancy and in turn triggers a return to estrus $[68,69]$. The Bruce effect is mediated by $\mathrm{VN}$ excitatory projections from the AOB to the medial amygdala, the bed nucleus of the stria terminalis, the medial hypothalamus, and ultimately the dopaminergic neurons of the arcuate nucleus that control PRL release by the anterior pituitary [70]. PRL in mice is luteotrophic and its inhibition, mediated by the dopaminergic neurons of the arcuate nucleus, prevents blastocyst implantation [71]. The exteroceptive induction of estrus is lost by stud-male odours through enhancement of granule-to-mitral synaptic inhibition occurring in the $\mathrm{AOB}$ during a sensitive period around mating $[72,73]$ (Figure 1). This process involves a restricted pool of granule cells in the AOB, which actually inhibits for several weeks (50-60 days) mitral cell signal transmission to the forebrain areas involved in estrus induction $[72,73]$. Thus, although some of the molecular mechanisms underlying the mate pheromonal imprinting remain to be elucidated (see for detailed discussion [71]) and recent data suggest a possible involvement of some main $\mathrm{OB}$ neurons [74], more of four decades of intense investigation supports the idea that such memory process is elicited by male pheromonal cues and mainly targets the vomeronasal system.

Recently, we have proposed that $\mathrm{AN}$ in the $\mathrm{AOB}$ of female mice plays a critical role in the achievement of this memory process [12], which implies a direct link with reproductive behavior. In the next paragraphs we will discuss multiple experimental evidences supporting this hypothesis.

\section{The AOB Is a Site of Adult Constitutive Neurogenesis in Rodents}

We reported the presence of SVZ neuroblasts in the AOB (Figure 2(a)) of rats in 1997 [75]. Afterward, other studies from our [76] and other laboratories [31, 77] showed occurrence of immature neurons in the $\mathrm{AOB}$ of diverse mammalian species. Yet, clear evidence that SVZ neuroblasts do integrate within the mature circuits of the mouse $\mathrm{AOB}$ was obtained only later, when, by using multiple approaches, it was definitively demonstrated that neuroblasts reaching this region acquire phenotypic and anatomical features consistent with those of functional neurons, mostly granule cells (Figures 2(b) and 2(c)), [19]. Subsequent studies have confirmed this evidence $[12,29,30]$, which indicates that the $A O B$, just as the MOB and hippocampus, represents a site of adult constitutive neurogenesis (see for detailed discussion [78]). Since newborn neurons in the adult brain are an elective cellular substrate for mechanisms of memory formation [79], the hypothesis was made that $\mathrm{AN}$ in the $\mathrm{AOB}$ could serve for the mate pheromonal imprinting.

\section{Male Bedding Pheromones Modulate Neurogenesis in the AOB of Female Mice}

Sensory activity increases integration/survival of newborn neurons in the main $\mathrm{OB}$ during a critical time window of neuroblasts maturation [80-82]. Consistent with this "rule," long- (28 days) or short-term exposure (7 days) to male soiled bedding, which contains semiochemicals present in urine and exocrine glands secretion [83], significantly increases the number of new neurons in the AOB granule cell layer of adult females $[12,19,29,30]$. This effect is achieved favoring the integration of newborn cells aged between 7 and 14 days $[12,30]$, the critical time window for survival of $\mathrm{AOB}$ newborn neurons [19]. In addition, male bedding exposure can also increase $\mathrm{AOB}$ neurogenesis in females by promoting proliferation of SVZ progenitor cells [29]. Enhanced survival in the $\mathrm{AOB}$ occurs only in postpubertal females, whereas exposure to cues from both genders is ineffective in both adult males and prepubertal females [12]. These latter data indicate the effect of male pheromones on AN is gender specific and directed only to sexually mature animals.

\section{Nature of the Cues Affecting AOB Neurogenesis during Male Bedding Exploration}

Male bedding is enriched of urine, whose fractions (high- and low-molecular weight fractions; HMW, LMW) are known to contain cues able to elicit different olfactory-mediated reproductive behaviors [84]. Whole urine, as well as the urine fraction deprived of the major urinary proteins (MUPs) that represent principal components of the HMW urine fraction [83], increases $\mathrm{AOB}$ neurogenesis in female mice. In addition, the HMW fraction of male urine, treated with menadion to deprive it from all volatile ligands [85] and loaded onto female LMW urine fraction to stimulate investigation is ineffective on AOB neurogenesis [12]. These data strongly support that the cues affecting $\mathrm{AN}$ in the $\mathrm{AOB}$ of females during bedding exploration are comprised in the LMW fraction of male urine. It is to note that, although MUPs and their bound ligands play a crucial role in providing information in mouse territorial behavior and male individuality [86], the LMW fraction of urine is the most efficient in inducing the Bruce effect [69, 87].

\section{Circuits Involved in the Regulation of AOB Neurogenesis}

Chemosensory stimuli contained in the LMW fraction of male urine are sensed by both the main and the accessory 

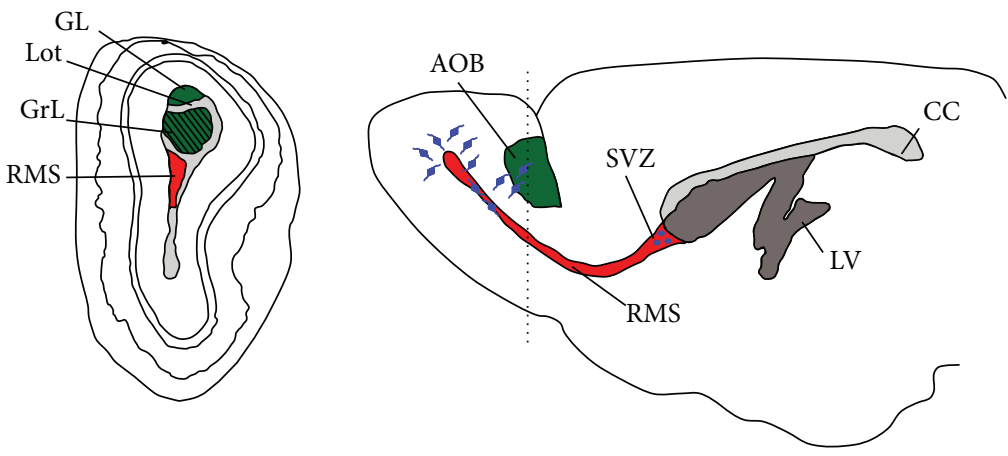

(a)
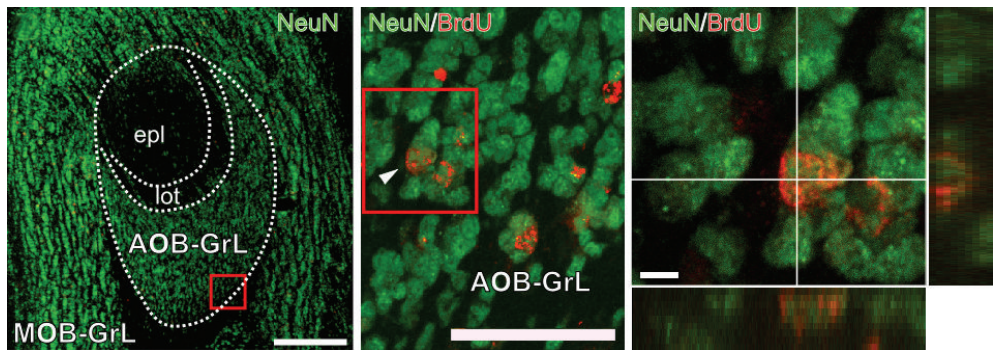

(b)
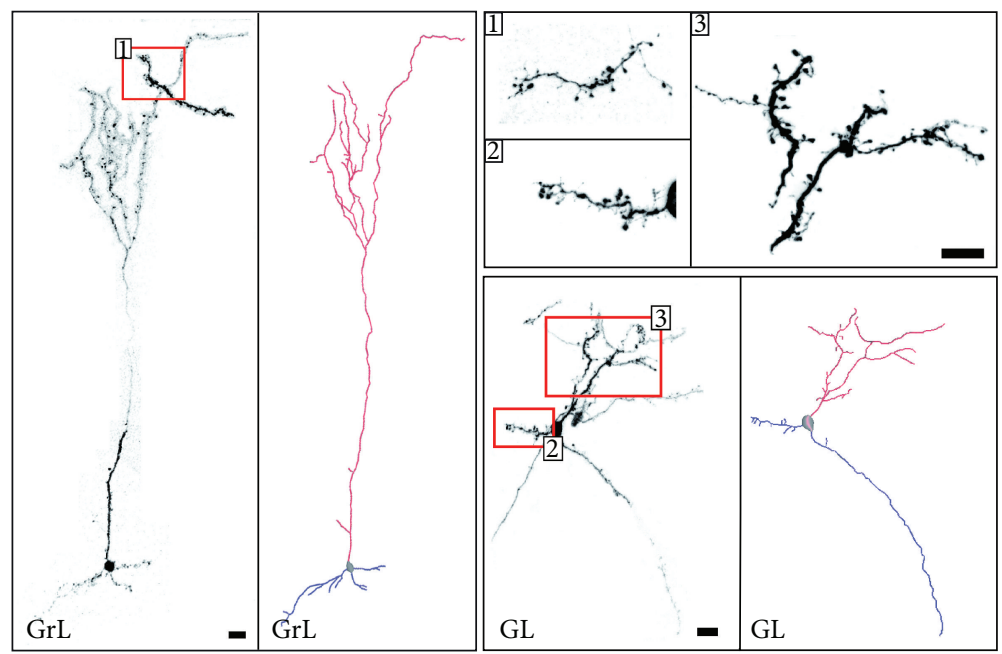

(c)

FIGURE 2: The accessory olfactory bulb is a site of adult constitutive neurogenesis. (a) Left, schematic representation of a posterior coronal section in the rat $\mathrm{OB}$ (cut at the level indicated by the dotted line) showing the anatomical organization of the AOB (green) and the RMS (red) in the core of the OB. Right, schematic representation of a parasagittal section of the rodent forebrain showing the position of the AOB (green) and the SVZ neurogenic niche from which neuroblasts migrate to both the MOB and AOB. (b) Coronal cross-section of the OB showing NeuN labeling in the MOB and AOB-GrL. At higher magnification, examples of BrdU/NeuN colabeled cells (see arrowhead) stained $15 \mathrm{~d}$ after the BrdU injection. Scale bars, left $200 \mu \mathrm{m}$, middle $50 \mu \mathrm{m}$, right $5 \mu \mathrm{m}$. (c) 3D reconstruction of EGFP-positive SVZ-derived precursors at 60 days after their homotopic transplantation in a wild type mouse [19]. EGFP-positive cells were found in the GrL and GL AOB layers. All cells show features of mature interneurons with well-developed dendritic arborization and spines, as visible at higher magnification. Scale bars, $100 \mu \mathrm{m}$ and $10 \mu \mathrm{m}$ (for higher magnification pictures). AOB: accessory olfactory bulb; MOB: main olfactory bulb; SVZ: subventricular zone; RMS: rostral migratory stream; LV: lateral ventricle; CC: corpus callosum; GrL: granular layer; lot: lateral olfactory tract; epl: external plexiform layer; GL: glomerular layer. ((b) was modified from [12] and (c) was modified from [19]).

olfactory systems [20]. To evaluate which sensory pathway drives enhanced AOB neurogenesis in females, the effects of genetic deletion of the Trpc2 cation channel, which leads to impaired VN function [88], were compared with those elicited by lesions of the main olfactory epithelium (MOE) caused by intranasal irrigation of zinc-sulfate $\left(\mathrm{ZnSO}_{4}\right)$ [89]. Enhanced AOB granule cell survival was absent in $\operatorname{trpc2^{-/-}}$ mice. By contrast, $\mathrm{ZnSO}_{4}$ lesion of the $\mathrm{MOE}$ did not abolish 

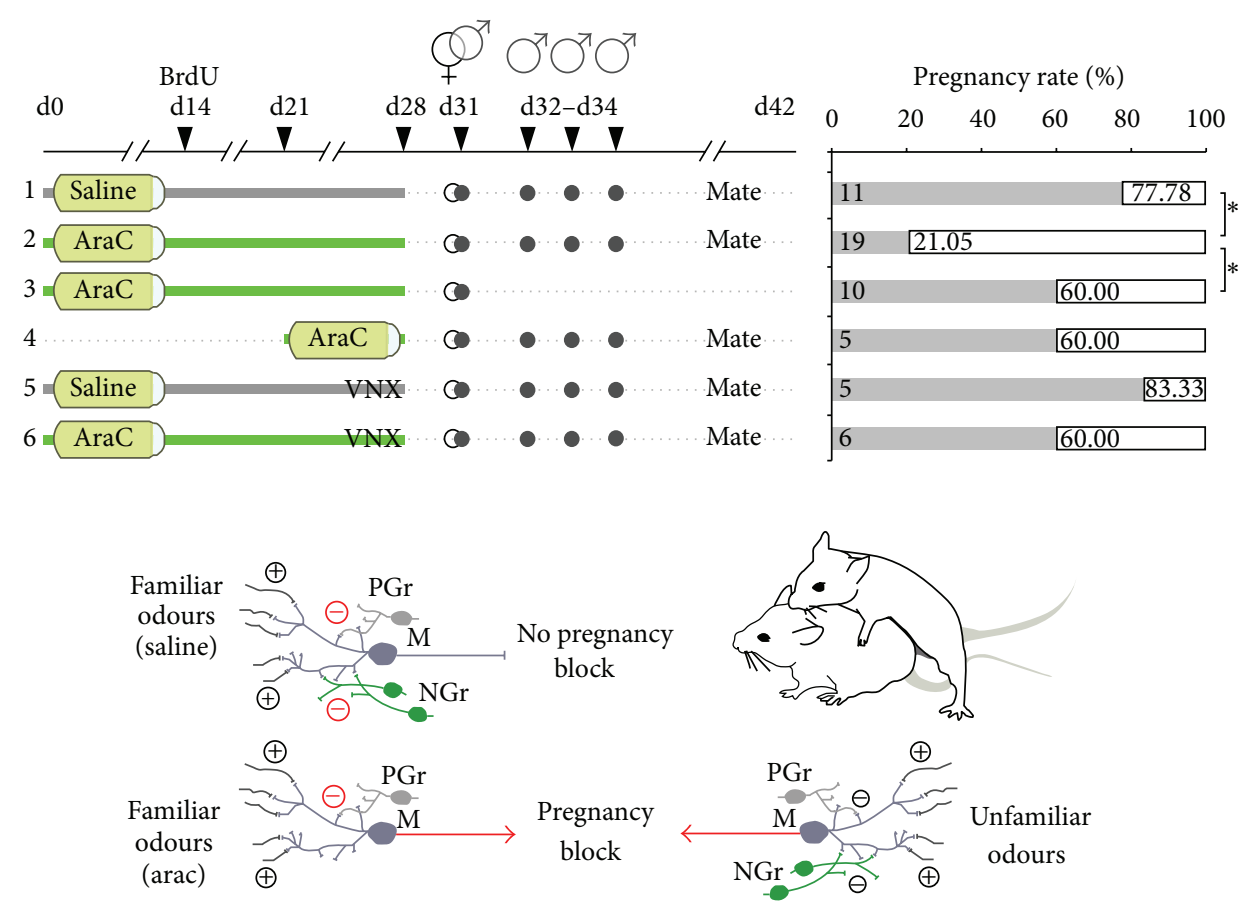

FIGURE 3: Functional involvement of AOB newborn neurons in the mate pheromonal imprinting. Mating and male olfactory stimulation (physical contact without intromission) on female mice after different protocols of Ara-C/saline treatment in normal and vomeronasal nervelesioned mice (VNX). In the graph the pregnancy rates are shown (in percentage) as a function of the different treatment conditions evaluated 11 days after mating. In the schematic diagram the role of AOB newborn granule cells is illustrated (NGr) in the modulation of mate's familiar signals (left side) and unfamiliar ones (right side): granule cells are preferentially involved in the detection of male individual odours once integrated into preexisting circuits. When highly responsive newborn granule cells (NGr) are eliminated after Ara-C treatment (left side, bottom), preexisting granule cells (PGr) are not sufficient to prevent pregnancy block by mate's familiar odours (red arrows). ${ }^{*} P<0.05$. (Figure modified from [12]).

enhanced neuronal survival in the $\mathrm{AOB}$, indicating that vomeronasal contact is necessary and sufficient to increase survival of new AOB granule cells [12]. This fact is in agreement with previous results showing that $\mathrm{AN}$ in the $\mathrm{AOB}$ is promoted only by direct contact with male soiled bedding (which implies vomeronasal activity) and not by its volatile compounds [19].

Cellular activity in the AOB can also be elicited by centrifugal inputs from the medial amygdala (MeA), even in absence of vomeronasal stimulation [90, 91]. Convergent olfactory and vomeronasal information reach the amygdala, which actually represents a key center for associative learning of male chemosensory cues [92]. Thus, male bedding exposure was performed after excitotoxic lesions to the MeA by injections of ibotenic acid [93]. Increased cell survival was detected in the AOB of sham-lesioned mice, but not in lesioned ones. Notably, granule cell survival in the main $\mathrm{OB}$ was unaffected by either bedding exposure or lesioning with ibotenic acid [12]. Together these results indicate that male pheromones specifically trigger integration of new $\mathrm{AOB}$ granule cells through $\mathrm{VN}$ centripetal and MeA centrifugal sensory activity. Other studies have shown that AN in the $\mathrm{OB}$ is regulated by concurrent peripheral sensory inputs and backward stimulation from central nuclei $[94,95]$. In such context, besides central stimuli from MeA, the important noradrenergic input reaching the $\mathrm{OB}$ from the locus coeruleus appears intriguing. Indeed, the noradrenergic signaling enhances survival/integration of newborn neurons in both main and accessory OB $[30,96]$. In parallel, it also sustains a form of olfactory perceptual learning in which previous experiences allow discrimination between perceptually similar odorants [97], thus supporting that contextual information rather than simple sensory peripheral activity is crucial to enhance the integration/survival of newborn neurons. Finally, the memory formation underlying the mate pheromonal imprinting is dependent on noradrenergic transmission in the AOB [71].

\section{Functional Involvement of AOB Neurogenesis in the Mate Pheromonal Imprinting}

Analysis of c-fos expression, as a marker of cellular activity [98], showed preferential responsiveness of AOB newborn neurons to male familiar (1-week experience) rather than unfamiliar (never experienced) stimuli [12]. This effect is evident soon after newborn cell integrates within the $\mathrm{AOB}$ circuits (around the 3rd week after their genesis) and is transient since it disappears after seven days. In addition, the same familiar cues induce attenuated responses (low cfos expression) in the vomeronasal nuclei involved in the 
control of estrus induction [12]. The above results support direct involvement of $\mathrm{AOB}$ newborn cells in male-individual recognition and are consistent with the idea that during a critical time-window of maturation newborn neurons can play unique sensory processing in the $\mathrm{OB}$ circuits $[5,6]$. Moreover, these data also suggest that the activity of newborn cells in the AOB circuits can modulate the responses of the central nuclei underlying the neuroendocrine reflex leading to the Bruce effect, which actually triggers a return to estrus. To test this hypothesis, the renewal of adult-born interneurons was blocked by administrating the antimitotic drug Ara-C during four weeks (the period of time covering the peak responsiveness to familiar stimuli of $\mathrm{AOB}$ newborn neurons). Other methods to ablate AN are available, such as X-ray irradiation [36] or gene-coded selective deletion [39]. Nevertheless, these procedures only partially delete SVZ neurogenesis [36] or require the use of tamoxifen [39], which can potentially interfere with estrogen-responsive regions, such as the vomeronasal system and adult SVZ $[99,100]$. By contrast, Ara-C infusion is particularly efficient to eliminate SVZ newborn neurons even after short-term treatments [101] and low doses of Ara-C have no gross aversive side effects $[96,102]$. Ara-C treated females were tested for the ability to recognize their mating partners in order to avoid the exteroceptive implantation failure. This was achieved by exposing Ara-C treated females during the postmating critical period ( 3 days after the beginning of mating in coincidence with the prolactin peaks $[69,87])$ to their mating partners (Figure 3). In contrast to saline treated females, high rate of pregnancy failure was detected in Ara-C treated mice, indicating the treatment switched the effect of familiar odour to that of an unfamiliar one. This was not due to a possible Ara-C induced infertility, since a group of Ara-C mated females not exposed during the critical postmating window showed normal pregnancy rate. Thus, ablation of bulbar neurogenesis compromises the formation of the stud male olfactory memory in female mice. To definitively rule out a potential involvement of $\mathrm{MOB}$ newborn neurons in this memory formation, a group of Ara-C treated females was tested for the mate pheromonal imprinting after surgical lesion of the vomeronasal nerves, a condition known to eliminate alone the exteroceptive pregnancy block $[103,104]$. This procedure was sufficient to prevent the high rate of pregnancy block by stud male exposure [12], showing the key role of $A O B$ newborn interneurons in this process and thus a direct link between $\mathrm{AN}$ and reproductive behavior. Importantly, other studies based on depletion of AN obtained through genetic targeting of newborn neurons in the forebrain [39] and/or focal irradiation of the SVZ [36] further support that continuous $\mathrm{OB}$ neurogenesis is required to sustain appropriate sex-specific behaviors.

\section{Concluding Remarks}

Social stimuli involved in the control of reproductive physiology enhance AN through complex mechanisms which imply multimodal integration and coordinated activity of the brain with the endocrine system. In turn, newborn neurons seem

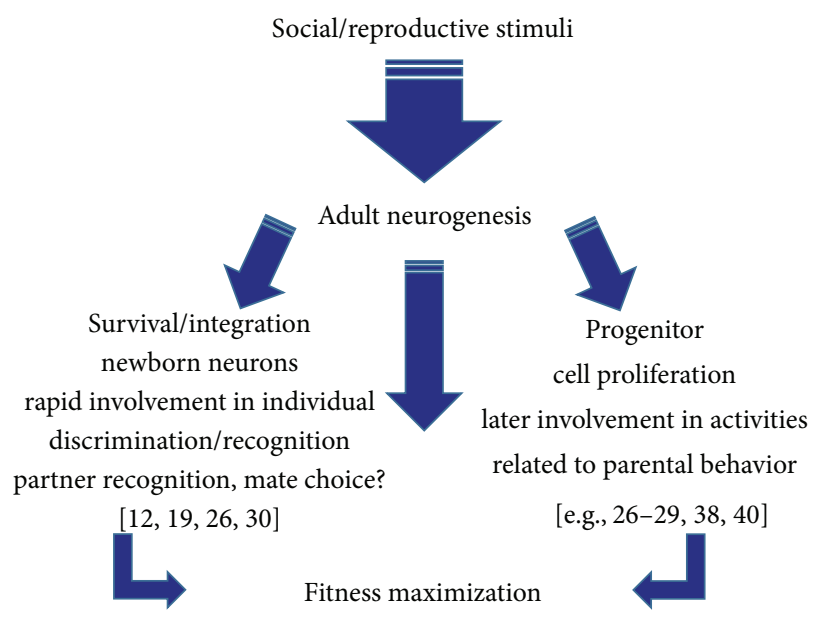

FIgURE 4: The double effect of social/reproductive stimuli on adult neurogenesis. Reproductive social stimuli positively influence adult neurogenesis by increasing the rate of proliferation of progenitor cells located in the adult germinative niches. This effect, which appears mediated by hormones and/or neurotransmitters released during intersexual and/or parent-offspring interaction, provides a reservoir of newborn neurons that after 2 weeks can be potentially involved in the regulation of parental behaviors. In parallel, socially relevant chemical cues (such as those conveyed by urine) also affect the integration/survival of newborn neurons already settled in the target region (e.g., AOB) during their critical time-window of selection. These additional newborn neurons are rapidly involved in mechanisms of individual discrimination/recognition and play a role in the mate pheromonal imprinting in the AOB of female mice, which is important to avoid pregnancy block. Thus, the positive effect exerted by reproductive social stimuli on AN seems directed to maximize the animal fitness.

to optimize/adapt the function of brain circuits underlying reproductive social behaviors. This feedback loop between AN and reproduction further confirms the role of adult neural plasticity in controlling this crucial physiological function and indicates that $\mathrm{AN}$ is a key actor of such regulation.

Additional analyses are required to clarify the cellular and molecular mechanisms by which already known external and internal cues modulate $\mathrm{AN}$ in reproductive behavior and to test the putative modulatory role on AN of other salient chemosensory factors, such as the exocrine gland-secreting peptide (ESP) 1 [105]. Additional work is needed also in order to enlighten the neural circuits which link AN and reproductive behavior. The vomeronasal pathway and some of its nuclei (e.g., medial amygdala) are important players in this process, but the extensive impact of reproductive social stimuli on different brain regions suggests that other circuits might be involved.

Finally, we would like to emphasize that regulation of AN by reproductive social cues in the $\mathrm{OB}$ occurs through a dual mechanism: (i) enhancing proliferation of progenitor cells in the SVZ and (ii) fostering survival of newborn neurons in the $\mathrm{AOB}$. Interestingly, in the hippocampus, acute running induces progenitor cell proliferation, but this effect does not lead to a corresponding net increase in neurogenesis if it is not associated with a prosurvival stimulus 
(i.e., environmental enrichment) [16, 106]. Similarly, the increase of SVZ progenitor proliferation primed by male chemosensory stimuli through hormones release (e.g., PRL) could become "functional" only if an additional appropriate prosurvival stimulus (e.g., chemosensory cues released by pups) eventually enhances newborn cell integration in the OB. By this additive effect, neurogenesis could optimize its function in specific behaviors related to the parental care [27, $28,46]$. In addition to the control on SVZ proliferation, the male chemosensory stimuli also act in parallel by enhancing survival/integration of pools of young newborn neurons in the OB $[19,30]$. These cells soon after, or during their integration into the circuits, are highly responsive to experienced/familiar male chemosensory cues, supporting that they can be directly involved in mechanisms of individual recognition/discrimination (Figure 4). Although the logic of this process deserves further investigation, it provides evidence that AN contributes to the reproductive function by affecting key activities related to the animal fitness.

\section{Conflict of Interests}

The authors declare that there is no conflict of interests regarding the publication of this paper.

\section{Acknowledgments}

This study is supported by PRIN 2010-2011 [2010599KBR_010] Peretto, University of Turin (ex 60\%) 2012-2013. The authors would like to thank Claudio Gendusa for his technical assistance. This work is dedicated to the memory of the authors' invaluable colleague and friend Prof. Maria Fosca Franzoni.

\section{References}

[1] P. Peretto and L. Bonfanti, "Major unsolved points in adult neurogenesis: doors open on a translational future?" Frontiers in Neuroscience, vol. 8, article 154, 2014.

[2] A. Sahay, D. A. Wilson, and R. Hen, "Pattern separation: a common function for new neurons in hippocampus and olfactory bulb," Neuron, vol. 70, no. 4, pp. 582-588, 2011.

[3] C. Mucignat-Caretta, M. Redaelli, and A. Caretta, "One nose, one brain: contribution of the main and accessory olfactory system to chemosensation," Frontiers in Neuroanatomy, vol. 9, no. 6, article 46, 2012.

[4] J. S. Snyder and H. A. Cameron, "Could adult hippocampal neurogenesis be relevant for human behavior?" Behavioural Brain Research, vol. 227, no. 2, pp. 384-390, 2012.

[5] A. Nissant, C. Bardy, H. Katagiri, K. Murray, and P. Lledo, "Adult neurogenesis promotes synaptic plasticity in the olfactory bulb," Nature Neuroscience, vol. 12, no. 6, pp. 728-730, 2009.

[6] S. S. P. Magavi, B. D. Mitchell, O. Szentirmai, B. S. Carter, and J. D. Macklis, "Adult-born and preexisting olfactory granule neurons undergo distinct experience-dependent modifications of their olfactory responses in vivo," The Journal of Neuroscience, vol. 25, no. 46, pp. 10729-10739, 2005.

[7] N. Kee, C. M. Teixeira, A. H. Wang, and P. W. Frankland, "Preferential incorporation of adult-generated granule cells into spatial memory networks in the dentate gyrus," Nature Neuroscience, vol. 10, no. 3, pp. 355-362, 2007.

[8] P. M. Lledo, M. Alonso, and M. S. Grubb, "dult neurogenesis and functional plasticity in neuronal circuits," Nature Reviews Neuroscience, vol. 7, no. 3, pp. 179-193, 2006.

[9] J. B. Aimone, W. Deng, and F. H. Gage, "Resolving new memories: a critical look at the dentate gyrus, adult neurogenesis, and pattern separation," Neuron, vol. 70, no. 4, pp. 589-596, 2011.

[10] C. D. Clelland, M. Choi, C. Romberg et al., "A functional role for adult hippocampal neurogenesis in spatial pattern separation," Science, vol. 325, no. 5937, pp. 210-213, 2009.

[11] D. J. Creer, C. Romberg, L. M. Saksida, H. van Praag, and T. J. Bussey, "Running enhances spatial pattern separation in mice," Proceedings of the National Academy of Sciences of the United States of America, vol. 107, no. 5, pp. 2367-2372, 2010.

[12] L. Oboti, R. Schellino, C. Giachino et al., "Newborn interneurons in the accessory olfactory promote mate recognition in female mice," Frontiers in Neuroscience, vol. 5, article 113, 2011.

[13] J. Freund, A. M. Brandmaier, L. Lewejohann et al., "Emergence of individuality in genetically identical mice," Science, vol. 340, no. 6133, pp. 756-759, 2013.

[14] D. K. Ma, W. R. Kim, G. L. Ming, and H. Song, "Activitydependent extrinsic regulation of adult olfactory bulb and hippocampal neurogenesis," Annals of the New York Academy of Sciences, vol. 1170, pp. 664-673, 2009.

[15] R. Faigle and H. Song, "Signaling mechanisms regulating adult neural stem cells and neurogenesis," Biochimica et Biophysica Acta: General Subjects, vol. 1830, no. 2, pp. 2435-2448, 2013.

[16] G. Kempermann, "Seven principles in the regulation of adult neurogenesis," European Journal of Neuroscience, vol. 33, no. 6, pp. 1018-1024, 2011.

[17] C. E. Feierstein, "Linking adult olfactory neurogenesis to social behavior," Frontiers in Neuroscience, vol. 6, article 173, 2012.

[18] P. Peretto and R. G. Parades, "Social cues, adult neurogenesis, and reproductive behavior," in Neurobiology of Chemical Comunication, C. Mucignat-Caretta, Ed., chapter 13, CRC Press, Boca Raton, Fla, USA, 2014.

[19] L. Oboti, G. Savalli, C. Giachino et al., "Integration and sensory experience-dependent survival of newly-generated neurons in the accessory olfactory bulb of female mice," European Journal of Neuroscience, vol. 29, no. 4, pp. 679-692, 2009.

[20] P. A. Brennan and F. Zufall, "Pheromonal communication in vertebrates," Nature, vol. 444, no. 7117, pp. 308-315, 2006.

[21] G. Gheusi, I. Ortega-Perez, K. Murray, and P. M. Lledo, "A niche for adult neurogenesis in social behavior," Behavioural Brain Research, vol. 200, no. 2, pp. 315-322, 2009.

[22] C. Dulac and T. Kimchi, "Neural mechanisms underlying sexspecific behaviors in vertebrates," Current Opinion in Neurobiology, vol. 17, no. 6, pp. 675-683, 2007.

[23] L. M. García-Segura, Hormones and Brain Plasticity, Oxford University Press, Oxford, UK, 2009.

[24] R. Tirindelli, M. Dibattista, S. Pifferi, and A. Menini, "From pheromones to behavior," Physiological Reviews, vol. 89, no. 3, pp. 921-956, 2009.

[25] M. T. Smith, V. Pencea, Z. Wang, M. B. Luskin, and T. R. Insel, "Increased number of BrdU-labeled neurons in the rostral migratory stream of the estrous prairie vole," Hormones and Behavior, vol. 39, no. 1, pp. 11-21, 2001.

[26] G. K. Mak, E. K. Enwere, C. Gregg et al., "Male pheromonestimulated neurogenesis in the adult female brain: possible role 
in mating behavior," Nature Neuroscience, vol. 10, no. 8, pp. 1003-1011, 2007.

[27] C. M. Larsen, I. C. Kokay, and D. R. Grattan, "Male pheromones initiate prolactin-induced neurogenesis and advance maternal behavior in female mice," Hormones and Behavior, vol. 53, no. 4, pp. 509-517, 2008.

[28] G. K. Mak and S. Weiss, "Paternal recognition of adult offspring mediated by newly generated CNS neurons," Nature Neuroscience, vol. 13, no. 6, pp. 753-758, 2010.

[29] A. Nunez-Parra, V. Pugh, and R. C. Araneda, "Regulation of adult neurogenesis by behavior and age in the accessory olfactory bulb," Molecular and Cellular Neuroscience, vol. 47, no. 4, pp. 274-285, 2011.

[30] J. H. Wu, Y. T. Han, J. Y. Yu, and T. W. Wang, "Pheromones from males of different familiarity exert divergent effects on adult neurogenesis in the female accessory olfactory bulb," Developmental Neurobiology, vol. 73, no. 8, pp. 632-645, 2013.

[31] L. Huang and E. L. Bittman, "Olfactory bulb cells generated in adult male golden hamsters are specifically activated by exposure to estrous females," Hormones and Behavior, vol. 41, no. 3, pp. 343-350, 2002.

[32] T. Shingo, C. Gregg, E. Enwere et al., "Pregnancy-stimulated neurogenesis in the adult female forebrain mediated by prolactin," Science, vol. 299, no. 5603, pp. 117-120, 2003.

[33] M. G. Ruscio, T. D. Sweeny, J. L. Hazelton, P. Suppatkul, E. Boothe, and C. S. Carter, "Pup exposure elicits hippocampal cell proliferation in the prairie vole," Behavioural Brain Research, vol. 187, no. 1, pp. 9-16, 2008.

[34] M. Furuta and R. S. Bridges, "Effects of maternal behavior induction and pup exposure on neurogenesis in adult, virgin female rats," Brain Research Bulletin, vol. 80, no. 6, pp. 408-413, 2009.

[35] M. Brus, M. Meurisse, I. Franceschini, M. Keller, and F. Lévy, "Evidence for cell proliferation in the sheep brain and its downregulation by parturition and interactions with the young," Hormones and Behavior, vol. 58, no. 5, pp. 737-746, 2010.

[36] C. E. Feierstein, F. Lazarini, S. Wagner et al., "Disruption of adult neurogenesis in the olfactory bulb affects social interaction but not maternal behavior," Frontiers in Behavioral Neuroscience, vol. 4, article 176, 2010.

[37] B. Leuner, E. R. Glasper, and E. Gould, "Sexual experience promotes adult neurogenesis in the hippocampus despite an initial elevation in stress hormones," PLoS ONE, vol. 5, no. 7, Article ID e11597, 2010.

[38] R. Corona, J. Larriva-Sahd, and R. G. Paredes, "Paced-mating increases the number of adult new born cells in the internal cellular (granular) layer of the accessory olfactory bulb," PLoS ONE, vol. 6, no. 5, Article ID e19380, 2011.

[39] M. Sakamoto, I. Imayoshi, T. Ohtsuka, M. Yamaguchi, K. Mori, and R. Kageyama, "Continuous neurogenesis in the adult forebrain is required for innate olfactory responses," Proceedings of the National Academy of Sciences of the United States of America, vol. 108, no. 20, pp. 8479-8484, 2011.

[40] W. Portillo, N. Unda, F. J. Camacho et al., "Sexual activity increases the number of newborn cells in the accessory olfactory bulb of male rats," Frontiers in Neuroanatomy, vol. 6, article 25, 2012.

[41] M. Keller, Q. Douhard, M. J. Baum, and J. Bakker, "Destruction of the main olfactory epithelium reduces female sexual behavior and olfactory investigation in female mice," Chemical Senses, vol. 31, no. 4, pp. 315-323, 2006.
[42] M. Keller, M. J. Baum, O. Brock, P. A. Brennan, and J. Bakker, "The main and the accessory olfactory systems interact in the control of mate recognition and sexual behavior," Behavioural Brain Research, vol. 200, no. 2, pp. 268-276, 2009.

[43] C. Rochefort, G. Gheusi, J. Vincent, and P. Lledo, "Enriched odor exposure increases the number of newborn neurons in the adult olfactory bulb and improves odor memory," Journal of Neuroscience, vol. 22, no. 7, pp. 2679-2689, 2002.

[44] J. Brown, C. M. Cooper-Kuhn, G. Kempermann et al., "Enriched environment and physical activity stimulate hippocampal but not olfactory bulb neurogenesis," European Journal of Neuroscience, vol. 17, no. 10, pp. 2042-2046, 2003.

[45] G. M. Arisi, M. L. Foresti, S. Mukherjee, and L. A. Shapiro, "The role of olfactory stimulus in adult mammalian neurogenesis," Behavioural Brain Research, vol. 227, no. 2, pp. 356-362, 2012.

[46] C. M. Larsen and D. R. Grattan, "Prolactin-induced mitogenesis in the subventricular zone of the maternal brain during early pregnancy is essential for normal postpartum behavioral responses in the mother," Endocrinology, vol. 151, no. 8, pp. 3805-3814, 2010.

[47] M. S. Erskine, "Prolactin release after mating and genitosensory stimulation in females," Endocrine Reviews, vol. 16, no. 4, pp. 508-528, 1995.

[48] D. R. Grattan and I. C. Kokay, "Prolactin: a pleiotropic neuroendocrine hormone," Journal of Neuroendocrinology, vol. 20, no. 6, pp. 752-763, 2008 .

[49] M. Numan and T. Insel, The Neurobiology of Parental Behavior, Springer, New York, NY, USA, 2003.

[50] B. Leuner, C. Mirescu, L. Noiman, and E. Gould, "Maternal experience inhibits the production of immature neurons in the hippocampus during the postpartum period through elevations in adrenal steroids," Hippocampus, vol. 17, no. 6, pp. 434-442, 2007.

[51] C. V. Rao and Z. M. Lei, "Consequences of targeted inactivation of LH receptors," Molecular and Cellular Endocrinology, vol. 187, no. 1-2, pp. 57-67, 2002.

[52] U. Boehm, Z. Zou, and L. B. Buck, "Feedback loops link odor and pheromone signaling with reproduction," Cell, vol. 123, no. 4, pp. 683-695, 2005.

[53] H. Yoon, L. W. Enquist, and C. Dulac, "Olfactory inputs to hypothalamic neurons controlling reproduction and fertility," Cell, vol. 123, no. 4, pp. 669-682, 2005.

[54] L. A. M. Galea, K. A. Uban, J. R. Epp et al., "Endocrine regulation of cognition and neuroplasticity: Our pursuit to unveil the complex interaction between hormones, the brain, and behaviour," Canadian Journal of Experimental Psychology, vol. 62, no. 4, pp. 247-260, 2008.

[55] Z. Hoyk, C. Varga, and Á. Párducz, "Estrogen-induced region specific decrease in the density of 5-bromo-2-deoxyuridinelabeled cells in the olfactory bulb of adult female rats," Neuroscience, vol. 141, no. 4, pp. 1919-1924, 2006.

[56] O. Brock, M. Keller, A. Veyrac, Q. Douhard, and J. Bakker, "Short term treatment with estradiol decreases the rate of newly generated cells in the subventricular zone and main olfactory bulb of adult female mice," Neuroscience, vol. 166, no. 2, pp. 368376, 2010.

[57] A. Veyrac and J. Bakker, "Postnatal and adult exposure to estradiol differentially influences adult neurogenesis in the main and accessory olfactory bulb of female mice," The FASEB Journal, vol. 25, no. 3, pp. 1048-1057, 2011. 
[58] J. Bakker and M. J. Baum, "Role for estradiol in femaletypical brain and behavioral sexual differentiation," Frontiers in Neuroendocrinology, vol. 29, no. 1, pp. 1-16, 2008.

[59] M. S. Erskine, "Solicitation behavior in the estrous female rat: a review," Hormones and Behavior, vol. 23, no. 4, pp. 473-502, 1989.

[60] R. G. Paredes and B. Vazquez, "What do female rats like about sex? Paced mating," Behavioural Brain Research, vol. 105, no. 1, pp. 117-127, 1999.

[61] I. Martínez and R. G. Paredes, "Only self-paced mating is rewarding in rats of both sexes," Hormones and Behavior, vol. 40, no. 4, pp. 510-517, 2001.

[62] R. G. Paredes, "Evaluating the neurobiology of sexual reward," ILAR Journal, vol. 50, no. 1, pp. 15-27, 2009.

[63] D. M. Arzate, W. Portillo, R. Corona, and R. G. Paredes, "Repeated paced mating promotes the arrival of more newborn neurons in the main and accessory olfactory bulbs of adult female rats," Neuroscience, vol. 232, pp. 151-160, 2013.

[64] A. Agmo and M. Gomez, "Sexual reinforcement is blocked by infusion of naloxone into the medial preoptic area," Behavioral Neuroscience, vol. 107, no. 5, pp. 812-818, 1993.

[65] R. G. Paredes and I. Martínez, "Naloxone blocks place preference conditioning after paced mating in female rats," Behavioral Neuroscience, vol. 115, no. 6, pp. 1363-1367, 2001.

[66] T. J. Sargeant, J. H. Miller, and D. J. Day, “Opioidergic regulation of astroglial/neuronal proliferation: where are we now?" Journal of Neurochemistry, vol. 107, no. 4, pp. 883-897, 2008.

[67] H. M. Bruce, "An exteroceptive block to pregnancy in the mouse," Nature, vol. 184, article 105, 1959.

[68] A. E. Rosser, C. J. Remfry, and E. B. Keverne, "Restricted exposure of mice to primer pheromones coincident with prolactin surges blocks pregnancy by changing hypothalamic dopamine release," Journal of Reproduction and Fertility, vol. 87, no. 2, pp. 553-559, 1989.

[69] T. Leinders-Zufall, P. Brennan, P. Widmayer et al., "MHC class I peptides as chemosensory signals in the vomeronasal organ," Science, vol. 306, no. 5698, pp. 1033-1037, 2004.

[70] C.-S. Li, H. Kaba, H. Saito, and K. Seto, "Excitatory influence of the accessory olfactory bulb on tuberoinfundibular arcuate neurons of female mice and its modulation by oestrogen," Neuroscience, vol. 29, no. 1, pp. 201-208, 1989.

[71] P. A. Brennan, "Outstanding issues surrounding vomeronasal mechanisms of pregnancy block and individual recognition in mice," Behavioural Brain Research, vol. 200, no. 2, pp. 287-294, 2009.

[72] P. Brennan, H. Kaba, and E. B. Keverne, "Olfactory recognition: a simple memory system,” Science, vol. 250, no. 4985, pp. 12231226, 1990.

[73] M. Matsuoka, H. Kaba, Y. Mori, and M. Ichikawa, "Synaptic plasticity in olfactory memory formation in female mice," NeuroReport, vol. 8, no. 11, pp. 2501-2504, 1997.

[74] C. Serguera, V. Triaca, J. Kelly-Barrett, M. A. Banchaabouchi, and L. Minichiello, "Increased dopamine after mating impairs olfaction and prevents odor interference with pregnancy," Nature Neuroscience, vol. 11, no. 8, pp. 949-956, 2008.

[75] L. Bonfanti, P. Peretto, A. Merighi, and A. Fasolo, "Newlygenerated cells from the rostral migratory stream in the accessory olfactory bulb of the adult rat," Neuroscience, vol. 81, no. 2, pp. 489-502, 1997.

[76] P. Peretto, C. Giachino, G. Panzica, and A. Fasolo, "Sexually dimorphic neurogenesis is topographically matched with the anterior accessory olfactory bulb of the adult rat," Cell and Tissue Research, vol. 306, no. 3, pp. 385-389, 2001.

[77] A. Martínez-Marcos, I. Ubeda-Bañón, and M. Halpern, "Cell migration to the anterior and posterior divisions of the granule cell layer of the accessory olfactory bulb of adult opossums," Developmental Brain Research, vol. 127, no. 1, pp. 95-98, 2001.

[78] L. Oboti and P. Peretto, "How neurogenesis finds its place in a hardwired sensory system," Frontiers in Neuroscience, vol. 6, article 117, 2014.

[79] M. Alonso, G. Lepousez, S. Wagner et al., "Activation of adult-born neurons facilitates learning and memory," Nature Neuroscience, vol. 15, no. 6, pp. 897-904, 2012.

[80] L. Petreanu and A. Alvarez-Buylla, "Maturation and death of adult-born olfactory bulb granule neurons: role of olfaction," Journal of Neuroscience, vol. 22, no. 14, pp. 6106-6113, 2002.

[81] B. Winner, C. M. Cooper-Kuhn, R. Aigner, J. Winkler, and H. G. Kuhn, "Long-term survival and cell death of newly generated neurons in the adult rat olfactory bulb," European Journal of Neuroscience, vol. 16, no. 9, pp. 1681-1689, 2002.

[82] M. Yamaguchi and K. Mori, "Critical period for sensory experience-dependent survival of newly generated granule cells in the adult mouse olfactory bulb," Proceedings of the National Academy of Sciences of the United States of America, vol. 102, no. 27, pp. 9697-9702, 2005.

[83] P. A. Brennan and E. B. Keverne, "Something in the air? New insights into mammalian pheromones," Current Biology, vol. 14, no. 2, pp. R81-R89, 2004.

[84] S. A. Roberts, D. M. Simpson, S. D. Armstrong et al., "Darcin: a male pheromone that stimulates female memory and sexual attraction to an individual male's odour," BMC Biology, vol. 8, article 75, 2010.

[85] P. Chamero, T. F. Marton, D. W. Logan et al., "Identification of protein pheromones that promote aggressive behaviour," Nature, vol. 450, no. 7171, pp. 899-902, 2007.

[86] J. L. Hurst, "Female recognition and assessment of males through scent," Behavioural Brain Research, vol. 200, no. 2, pp. 295-303, 2009.

[87] R. Peele, I. Salazar, M. Mimmack, E. B. Keverne, and P. A. Brennan, "Low molecular weight constituents of male mouse urine mediate the pregnancy block effect and convey information about the identity of the mating male," European Journal of Neuroscience, vol. 18, no. 3, pp. 622-628, 2003.

[88] B. G. Leypold, C. R. Yu, T. Leinders-Zufall, M. M. Kim, F. Zufall, and R. Axel, "Altered sexual and social behaviors in trp2 mutant mice," Proceedings of the National Academy of Sciences of the United States of America, vol. 99, no. 9, pp. 6376-6381, 2002.

[89] K. McBride, B. Slotnick, and F. L. Margolis, "Does intranasal application of zinc sulfate produce anosmia in the mouse? An olfactometric and anatomical study," Chemical Senses, vol. 28, no. 8, pp. 659-670, 2003.

[90] D. E. Pankevich, J. A. Cherry, and M. J. Baum, "Accessory olfactory neural Fos responses to a conditioned environment are blocked in male mice by vomeronasal organ removal," Physiology and Behavior, vol. 87, no. 4, pp. 781-788, 2006.

[91] K. L. Martel and M. J. Baum, "A centrifugal pathway to the mouse accessory olfactory bulb from the medial amygdala conveys gender-specific volatile pheromonal signals," European Journal of Neuroscience, vol. 29, no. 2, pp. 368-376, 2009.

[92] J. Moncho-Bogani, F. Martinez-Garcia, A. Novejarque, and E. Lanuza, "Attraction to sexual pheromones and associated odorants in female mice involves activation of the reward system and 
basolateral amygdala," European Journal of Neuroscience, vol. 21, no. 8, pp. 2186-2198, 2005.

[93] F. Chauveau, C. Piérard, M. Coutan, I. Drouet, P. Liscia, and D. Béracochéa, "Prefrontal cortex or basolateral amygdala lesions blocked the stress-induced inversion of serial memory retrieval pattern in mice," Neurobiology of Learning and Memory, vol. 90, no. 2, pp. 395-403, 2008.

[94] L. Oboti and J. C. Platel, "Brain control of olfaction via topdown regulation on adult neurogenesis," Frontiers in Neuroscience, vol. 6, no. 6, article 117, 2012.

[95] G. Lepousez, M. T. Valley, and P. Lledo, "The impact of adult neurogenesis on olfactory bulb circuits and computations," Annual Review of Physiology, vol. 75, pp. 339-363, 2013.

[96] M. M. Moreno, C. Linster, O. Escanilla, J. Sacquet, A. Didier, and N. Mandairon, "Olfactory perceptual learning requires adult neurogenesis," Proceedings of the National Academy of Sciences of the United States of America, vol. 106, no. 42, pp. 17980-17985, 2009.

[97] M. M. Moreno, K. Bath, N. Kuczewski, J. Sacquet, A. Didier, and N. Mandairon, "Action of the noradrenergic system on adultborn cells is required for olfactory learning in mice," The Journal of Neuroscience, vol. 32, no. 11, pp. 3748-3758, 2012.

[98] J. I. Morgan, D. R. Cohen, J. L. Hempstead, and T. Curran, "Mapping patterns of C-fos expression in the central nervous system after seizure," Science, vol. 237, no. 4811, pp. 192-197, 1987.

[99] U. Halbreich and L. S. Kahn, "Selective oestrogen receptor modulators current and future brain and behaviour applications," Expert Opinion on Pharmacotherapy, vol. 1, no. 7, pp. 1385-1398, 2000.

[100] N. A. Kedia-Mokashi, R. Mugasimangalam, M. Aiyaz, S. Mukherjee, and N. H. Balasinor, "Aberrant expression of imprinted genes in post-implantation rat embryos," Life Sciences, vol. 88, no. 13-14, pp. 634-643, 2011.

[101] V. Breton-Provencher, M. Lemasson, M. R. Peralta III, and A. Saghatelyan, "Interneurons produced in adulthood are required for the normal functioning of the olfactory bulb network and for the execution of selected olfactory behaviors," The Journal of Neuroscience, vol. 29, no. 48, pp. 15245-15257, 2009.

[102] F. Lazarini and P. Lledo, "Is adult neurogenesis essential for olfaction?" Trends in Neurosciences, vol. 34, no. 1, pp. 20-30, 2011.

[103] J. F. Bellringer, P. M. Hester Pratt, and E. B. Keverne, "Involvement of the vomeronasal organ and prolactin in pheromonal induction of delayed implantation in mice," Journal of Reproduction and Fertility, vol. 59, no. 1, pp. 223-228, 1980.

[104] M. Matsuoka, M. Norita, and R. M. Costanzo, "A new surgical approach to the study of vomeronasal system regeneration," Chemical Senses, vol. 30, no. 1, pp. 129-130, 2005.

[105] H. Kimoto, S. Haga, K. Sato, and K. Touhara, "Sex-specific peptides from exocrine glands stimulate mouse vomeronasal sensory neurons," Nature, vol. 437, no. 7060, pp. 898-901, 2005.

[106] K. Fabel, S. A. Wolf, D. Ehninger, H. Babu, P. Leal-Galicia, and G. Kempermann, "Additive effects of physical exercise and environmental enrichment on adult hippocampal neurogenesis in mice," Frontiers in Neuroscience, vol. 3, article 50, 2009. 

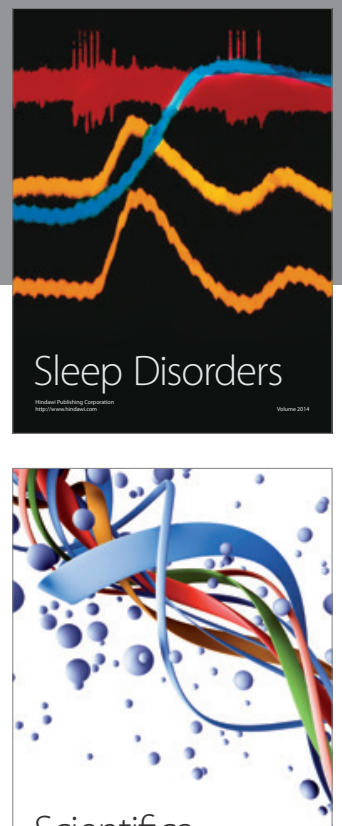

Scientifica
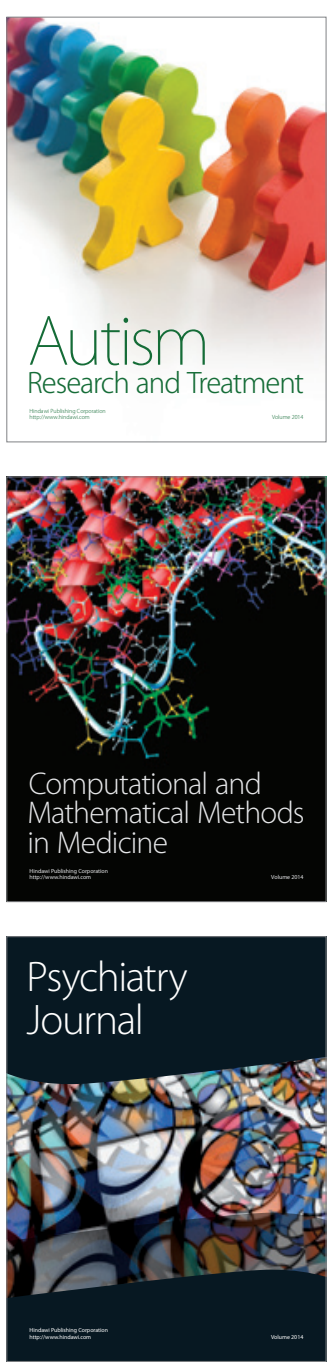
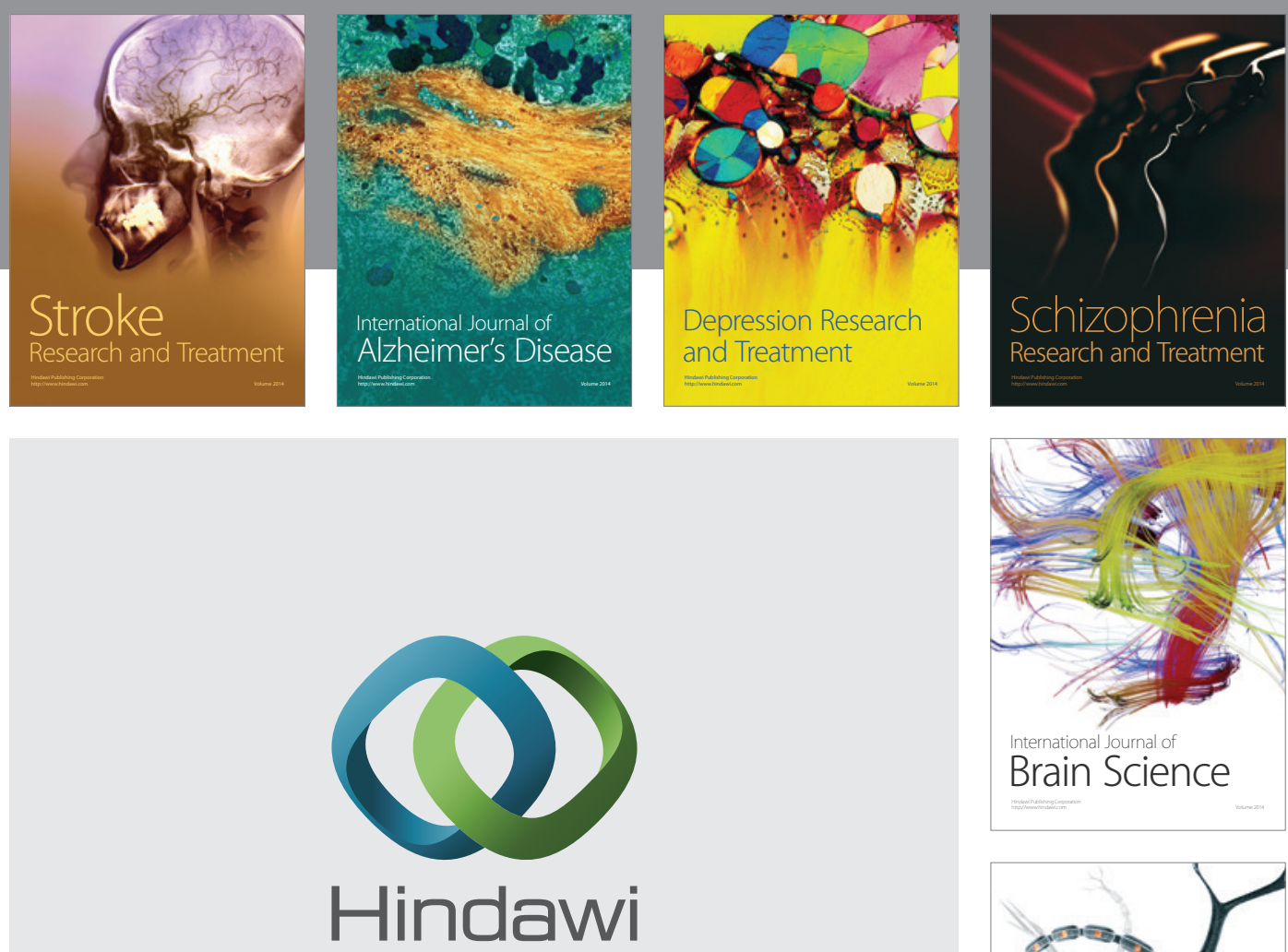

Submit your manuscripts at

http://www.hindawi.com
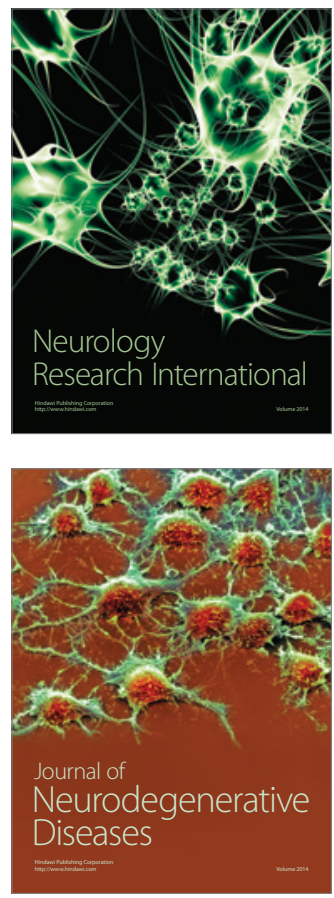

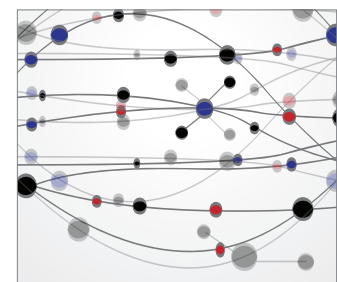

The Scientific World Journal
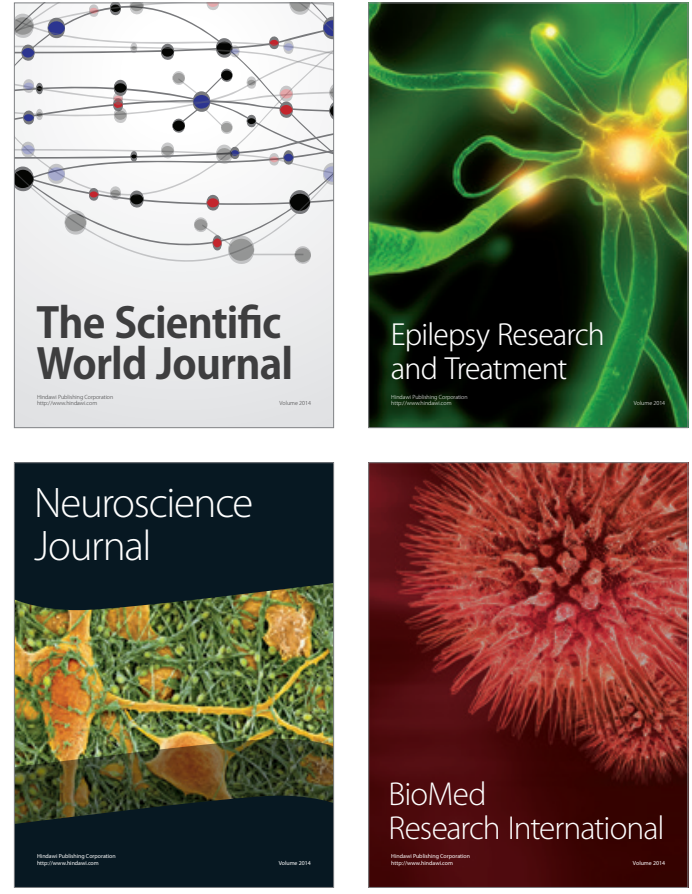

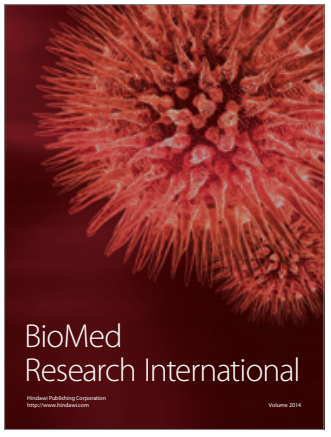

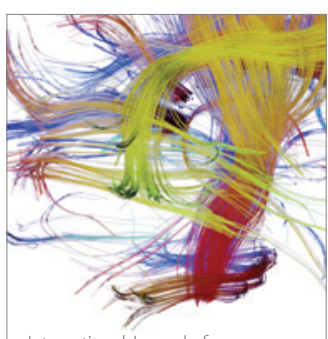

Brain Science

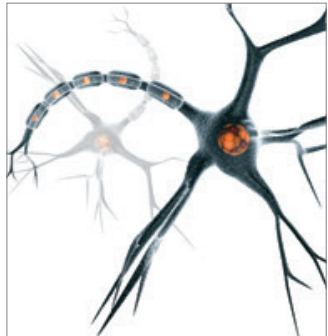

Neural Plasticity
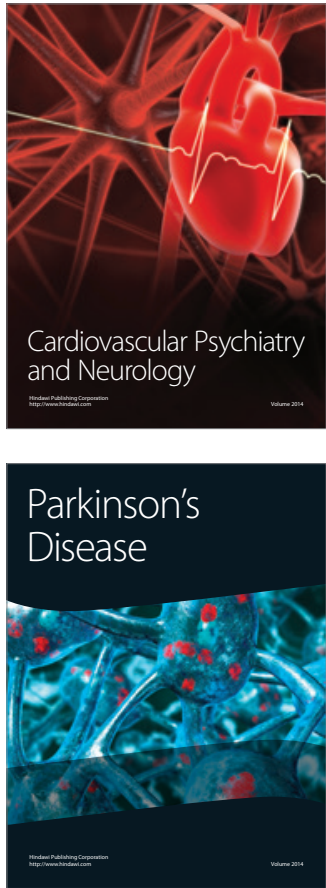